\title{
Test guidelines for evaluation real driving emission two-way vehicles
}

\author{
Michalina Kamińska ${ }^{1, *}$, Lukasz Rymaniak ${ }^{1}$, Pawet Daszkiewicz ${ }^{1}$ and Piotr Lijewski ${ }^{1}$ \\ ${ }^{1}$ Faculty of Transport Engineering, Poznan University of Technology, Poland
}

\begin{abstract}
The article discusses the results of tests carried out under real operating conditions, based on which a custom test for road-rail vehicles was developed. The proposed test reflects the working conditions in which road-rail vehicles are used. The measurements were performed for a vehicle equipped with an internal combustion engine during five stages of operation. Measuring cycles included driving on a paved road, rolling on tracks and running on a track without load, with a load of 90 tons and with a load of 140 tons. The article compares the legislative guidelines with actual operation, thanks to which guidelines for the road-rail test for assessing the exhaust emission of harmful gases were developed. Based on the recorded data, a test proposal was described, taking into account the operating time share during the test, the average speed of travel and the duration of the test cycle. In addition, guidelines on the test procedure in the proposed test are discussed.
\end{abstract}

\section{1 introduction}

The type approval tests concerning the exhaust emission of harmful gases emitted from non-road vehicles are carried out on the engine dynamometer. Dynamometer measurements are to some extent designed to simulate the conditions of actual engine operation, but they are far from the real parameters of their operation. As proven in [1-7], the test cycles described do not reflect the real operating conditions. Thus, the test results do not make it possible to analyze the vehicle's real impact on the environment and human health. The qualitative and quantitative measurements of exhaust emissions in laboratory conditions often differ from the actual emission of exhaust gases. This is mainly due to the large variety of machines and vehicles that fall into the NRMM (Non-Road Mobile Machinery) group. In order to obtain reliable results, it is necessary to carry out tests in real operating conditions, similarly to road vehicles (cars and heavy vehicles). Currently, for passenger cars and heavy vehicles, tests are carried out in road conditions as described by the RDE (Real Driving Emissions) tests. These tests enable the verification of vehicles ecological indicators in a wide spectrum of their drive systems and allow to determine the conformity of their operation related to the relevant type approval standards. Such tests also make it possible to take into account the local ambient conditions.

The development of motor vehicles is primarily aimed at reducing their negative impact on the natural environment. This is achieved mainly through the introduction of new technologies in their construction. This applies to individual parts (improvement of the material quality) as well as entire propulsion systems, e.g. by their hybridization. In recent years, substituting the mechanical drive in functional systems (power steering, air conditioning, heating, etc.) with electric solutions is becoming increasingly popular in off-road and heavy vehicles, which requires the improvement of electrical systems parameters and the use of innovative solutions [8-10]. Road-rail vehicles are becoming more and more popular. Their functionality and operation economics allow for their wider use not only on the railway, but also in complex storage systems. Therefore, the proposed research activities become necessary to include them in various types of warehouse processes for example by determining the economic balance. These results can be an extension to process analyzes, such as [11]. The implementation of the presented works can also be used in the analysis of the vehicle's life cycle. Measurements of emissions in various test drive cycles allow to determine the level of vehicle wear, as well as the wear of individual elements (mainly the engine construction solutions and exhaust aftertreatment systems). Such activities allow for detailed simulation and calculations of fleet operational costs, an example of such considerations is presented in [12]

\section{Current legal regulations concerning the exhaust emissions measurement in road-rail vehicles}

In the European Union, combustion engines used in NRMM (Non-Road Mobile Machinery) vehicles are tested using two test cycles. The total emission of pollutants measured in tests must not exceed the limit values defined in $[97 / 68 / \mathrm{EC}]$.

The NRSC (Non-Road Stationary Cycle) test is a stationary cycle used to measure the emission of gaseous compounds and particulates. It is carried out for Stage I-

Corresponding author: michalina.kaminska@put.poznan.pl 
IV norms for CI engines with a net power of $19 \mathrm{~kW} \leq \mathrm{P}$ $\leq 560 \mathrm{~kW}$ operating at constant or variable speed. The test consists of a number of speed and load phases that cover the typical range of $\mathrm{CI}$ engines operating points used in off-road vehicles. For each of the test phases, the concentration of the tested exhaust component, the exhaust gas flow rate as well as the power and weighted averages of the measured values are determined. In a fixed sequence of operating conditions sets, the heated engine is tested continuously by taking a sample of the raw exhaust gas from the exhaust system. Particulate measurement is carried out by diluting the sample with conditioned air and passing such a prepared mixture through the filter (one sample for the entire test). The sample can also be collected on separate filters, one for each phase tested, and then the weighted average values for the entire test are calculated. The number of grams of each pollutant per kilowatt-hour is calculated in a strictly defined way. The test includes characteristics showing how to conduct a test cycle for the various devices defined in Directive [2004/26 / EC].

The NRTC (Non-Road Transient Cycle) test is a nonstationary cycle used to measure gaseous compounds and particulates emission. It is carried out as a part of Stage IIIB and IV norms for CI engines with net power in the range of $19 \mathrm{~kW} \leq \mathrm{P} \leq 560 \mathrm{~kW}$, working at variable speeds. It is important to take into account the variability of engine operation parameters. Two cycles are performed as a part of the test. The cold start cycle consists of conditioning the engine at $20-30^{\circ} \mathrm{C}$. It is carried out after natural or forced cooling of the engine. The hot start cycle is performed in a warm state, 20 minutes after conditioning, immediately after the first cycle. During the test, the total exhaust emission of harmful compounds is obtained. The work output generated by the engine over the entire test cycle is determined by integrating power versus cycle time, using torque feedback and rotational speed brakes. The concentration of gaseous components for the entire test cycle can be determined using two methods. The first method is to measure the components concentration in the raw exhaust gas by integrating the analyzer signal in accordance with the procedure described in Directive [2010/26/EU]. It is also possible to measure the concentration in the raw exhaust gas in the CVS (Constant Volume Sample) system. Particulate measurement is carried out by taking a sample of exhaust gas through a suitable filter by means of a full or partial dilution method. The flow rate of diluted or nondiluted exhaust gas throughout the cycle is determined depending on the method used. To determine the mass of each pollutant measured per kilowatt-hour, the mass emission value is divided by the work output of the tested vehicle. The emission expressed in $\mathrm{g} / \mathrm{kWh}$ is measured during each test drive cycle, for cold and hot start. The total exhaust emission is determined by applying $10 \%$ weight for cold start and $90 \%$ for hot start results.

Based on the operating parameters determined in the NRTC test, the time density characteristics were created as a function of engine rotational speed - load (rpm-Nm), as shown in Fig. 1. The distribution of operating parameters expressed in $\%$ is presented in half-closed intervals. The largest operating time share in single operating point $(7.4 \%)$ occurs in the speed range of $\langle 0 \%$; $10 \%\rangle$ and load of $\langle 0 \% ; 10 \%\rangle$. The highest time density can be found for the range characterized by engine speed of $\langle 50 \% ; 110 \%\rangle$ and small and average torque values in the range $\langle 0 \% ; 60 \%\rangle$, in which the obtained values exceed 50\%. Parameters exceeding $100 \%$ for the crankshaft speed are a result of the test methodology used, which requires temporarily overloadinf the engine during the test cycle.

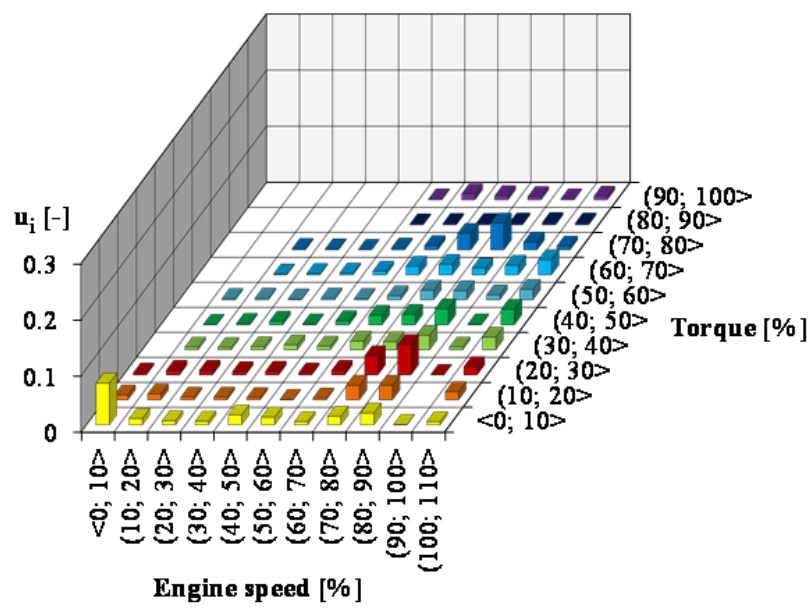

Fig. 1. Time densities for a standardized NRTC test in engine speed and load ranges

\section{Test methodology}

A road-rail tractor was used in the conducted tests (fig. 2, Table 1), it was equipped with an engine with a maximum power of $116 \mathrm{~kW}$ and a maximum torque of $640 \mathrm{Nm}$. According to the technical data, the vehicle complied with the Stage IV emission norms, thanks to, among others, exhaust aftertreatment systems, such as: DOC (Diesel Oxidation Catalyst) and DPF (Diesel Particulate Filter). The vehicle had a maximum traction power of $45 \mathrm{kN}$ on the track and $55 \mathrm{kN}$ on the road. The maximum speed was $25 \mathrm{~km} / \mathrm{h}$.

Table 1. Test vehicle parameters

\begin{tabular}{|l|c|}
\hline \multicolumn{1}{|c|}{ Parametr } & Wartość \\
\hline Maximum power & $116 \mathrm{~kW}$ \\
\hline Maximum torque & $640 \mathrm{Nm}$ \\
\hline Exhaust emission norm & Stage IV \\
\hline Maximum pull on road & $55 \mathrm{kN}$ \\
\hline Maximum pull on track & $45 \mathrm{kN}$ \\
\hline Vehicle mass & $8200 \mathrm{~kg}$ \\
\hline Pull weight limit & $140 \mathrm{tons}$ \\
\hline Maximum vehicle speed on road/track & $25 \mathrm{~km} / \mathrm{h}$ \\
\hline
\end{tabular}


The road-rail tractor was adapted to move both on the dirt road and railway tracks thanks to the use of circular guiding rollers to move along the tracks together with traction and buffer devices. Equipping the vehicle with additional devices made it possible to perform maneuver work necessary for the tests to be carried out.

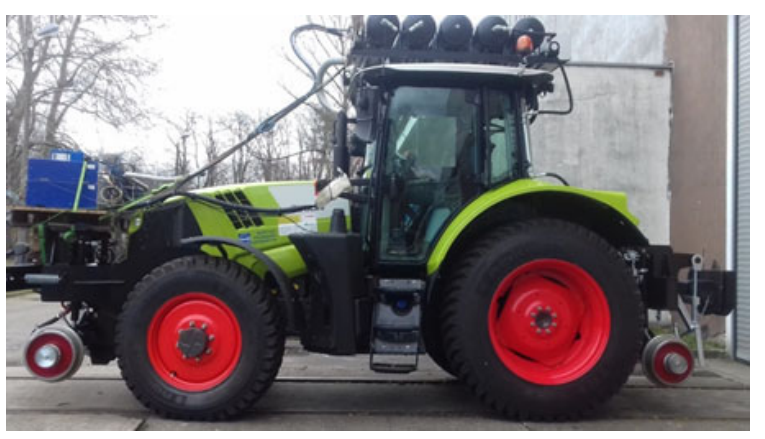

Fig. 2. Tested vehicle - road-rail tractor

The PEMS (Portable Emissions Measurement System) measuring equipment was used to carry out the exhaust emissions measurements in real operating conditions of a road-rail vehicle. The concentration measurement of exhaust gases and its mass flow was made using the mobile SEMTECH DS apparatus. The exhaust emissions measurement was done by sending the gas sample into the device via a measuring probe maintaining the temperature of $191^{\circ} \mathrm{C}$ (in order to prevent the condensation of hydrocarbons before measurement). The device would then filter the solid particles from the exhaust gases that could affect the proper operation of the apparatus. The HC concentration is measured using the FID (Flame Ionization Detector) analyzer. The exhaust gases are further cooled down to $4^{\circ} \mathrm{C}$, after which the measurement of the concentration of nitrogen oxides is carried out using the NDUV method (Non-Dispersive Ultraviolet). The concentration of $\mathrm{CO}$ and $\mathrm{CO}_{2}$ is determined by using the NDIR method (Non-Dispersive Infra Red).

The measurement of particulate concentration was carried out using the AVL MSS 483 mobile analyzer (Micro Soot Sensor). This device operates based on the photoacoustic method, which enables high accuracy measurement (down to $1 \mu \mathrm{g} / \mathrm{m}^{3}$ ). The gas sample volume in the resonant measuring chamber is alternately heated and cooled. This affects the creation of vibrations of the elastic medium. Vibrations are recorded by sensitive microphones as a sound wave, and the concentration of solid particles is directly proportional to the generated sound characteristics.

The tests were supplemented with the ambient air measurement using the Micro PEMS Axion R/S+ mobile analyzer, which made it possible to also take into account the atmospheric pollution. Using the nondispersive NDIR infrared analyzer and the electrochemical analyzer, the concentrations of gaseous compounds $\left(\mathrm{CO}_{2}, \mathrm{CO}, \mathrm{HC}, \mathrm{NO}_{\mathrm{x}}\right)$ were measured. A method based on the Laser Scatter effect (the measurement of particle velocity) was used to measure the particle concentration.
Data from the vehicle's diagnostic system was sent directly to the central measuring equipment unit. This allowed for continuous recording of the engine operating parameters (crankshaft speed, load generated). During the tests, a GPS position signal (Global Positioning System) was used to determine the position as well as the speed of the vehicle.

The research was divided into five stages. The first stage included the vehicle driving along an unpaved dirt road. Then the road-rail vehicle was rolled onto the railways. The third stage included a tractor equipped with a wheel set driving on the track without additional load. Then a load of 90 tons was added to the vehicle. The last stage consisted of driving with an extra load of 140 tons. Traffic parameters describing the performed test cycles are presented in Table 2.

Table 2. Driving parameters of the test vehicle

\begin{tabular}{|c|l|c|c|c|c|}
\hline \multirow{2}{*}{ No. } & \multirow{2}{*}{$\begin{array}{c}\text { Test drive } \\
\text { cycle }\end{array}$} & \multicolumn{4}{|c|}{ Parameter } \\
\cline { 3 - 6 } & $\begin{array}{c}\mathrm{V}_{\max } \\
{[\%]}\end{array}$ & $\begin{array}{c}\mathrm{V}_{\text {sr }} \\
{[\%]}\end{array}$ & $\begin{array}{c}\mathrm{s} \\
{[\%]}\end{array}$ & $\begin{array}{c}\mathrm{t} \\
{[\%]}\end{array}$ \\
\hline I & $\begin{array}{l}\text { Dirt road } \\
\text { driving }\end{array}$ & 72 & 26 & 28 & 12 \\
\hline II & $\begin{array}{l}\text { Moving onto } \\
\text { the rail tracks }\end{array}$ & - & - & - & - \\
\hline III & $\begin{array}{l}\text { Track driving } \\
\text { with no load }\end{array}$ & 36 & 15 & 24 & 18 \\
\hline IV & $\begin{array}{l}\text { Track driving } \\
\text { with a load of } \\
90 \text { tons }\end{array}$ & 36 & 8 & 38 & 48 \\
\hline V & $\begin{array}{l}\text { Track driving } \\
\text { with a load of } \\
140 \text { tons }\end{array}$ & 18 & 2 & 10 & 22 \\
\hline I-V & Whole test & 72 & 10 & 100 & 100 \\
\hline
\end{tabular}

\section{Operating parameters in real use}

In order to develop the driving cycle, an analysis of road tests was carried out. For the measurements performed, the operating time shares were determined in the speed and load ranges of the test vehicle at individual stages of the test cycle and for the journey as a whole. All research stages were characterized by the highest values of time density, exceeding $60 \%$ in the low rotational speeds range of $\langle 0 \% ; 30 \%\rangle$ and at small loads $(10 \% ; 30 \%\rangle$. For road travel (Fig. 3) and track travel (Fig. 5) without load, the operating points were distributed mostly in the ranges of small and medium values of engine operating parameters $\langle 0 \% ; 50 \%\rangle$ and $(10 \% ; 40 \%\rangle$, where their share was more than $85 \%$ of the total drive time. Moving the test vehicle onto tracks (Figure 4) was characterized by a $98 \%$ share of operating time in a very narrow range of parameter values, defined by the speed range of $\langle 0 \%$; $10 \%\rangle$ and torque range of $(10 \% ; 30 \%\rangle$. The largest range of work parameters was found for a 90-ton load track drive (Fig. 6), for which the highest time-density values $(85 \%)$ were obtained for almost the entire range of the rotational speed with a load in the range of $(10 \% ; 40 \%)$. When driving with a load of 120 tons (Fig. 7), the largest 
work time (83\%) was obtained for the smallest ranges of engine operation parameters $\langle 0 \% ; 10 \%\rangle$ and $\langle 0 \% ; 20 \%\rangle$. In Figure 8 a set of characteristics is presented which is a summary of all stages of research.

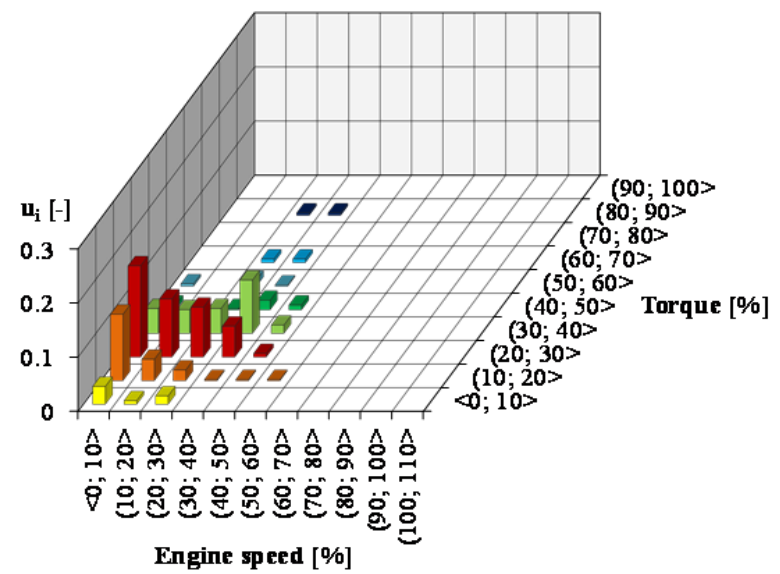

Fig. 3. Time density characteristic for the vehicle driving along the road without load presented in the engine speed and load intervals

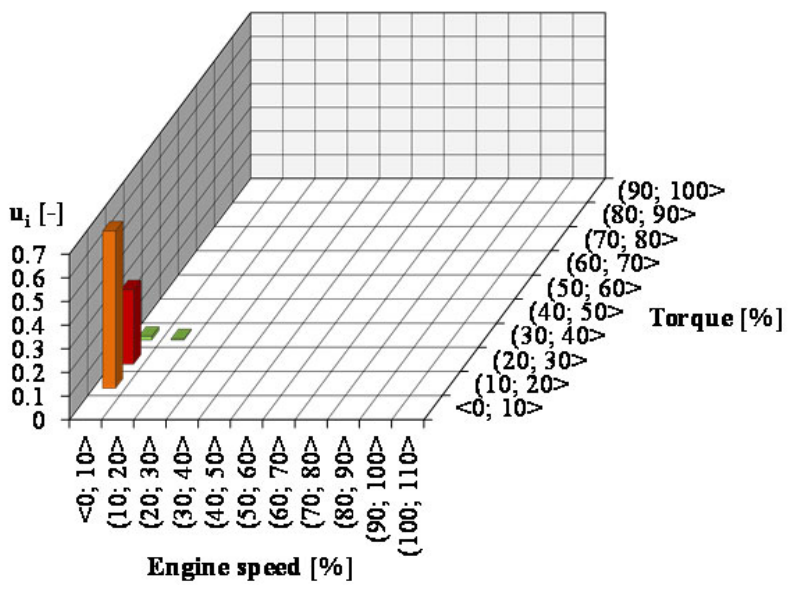

Fig. 4. Time density characteristic for the vehicle being moved onto rail tracks presented in the engine speed and load intervals

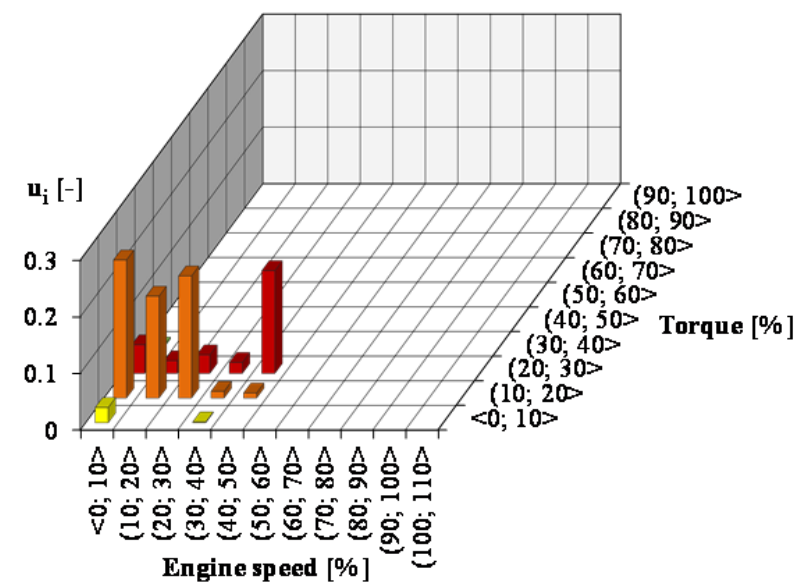

Fig. 5. Time density characteristic for the vehicle driving on the track without load presented in the engine speed and load intervals

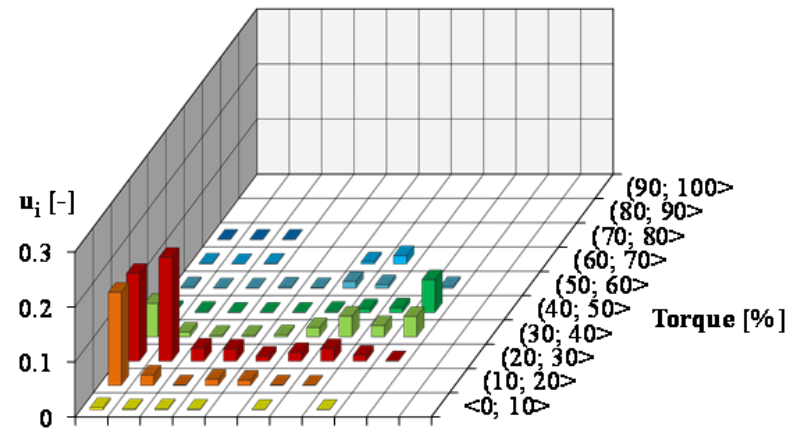

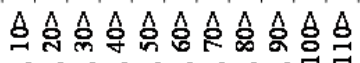

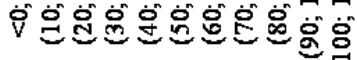

Engine speed [\%]

Fig. 6. Time density characteristic for the vehicle driving on the track with a load of 90 tons presented in the engine speed and load intervals

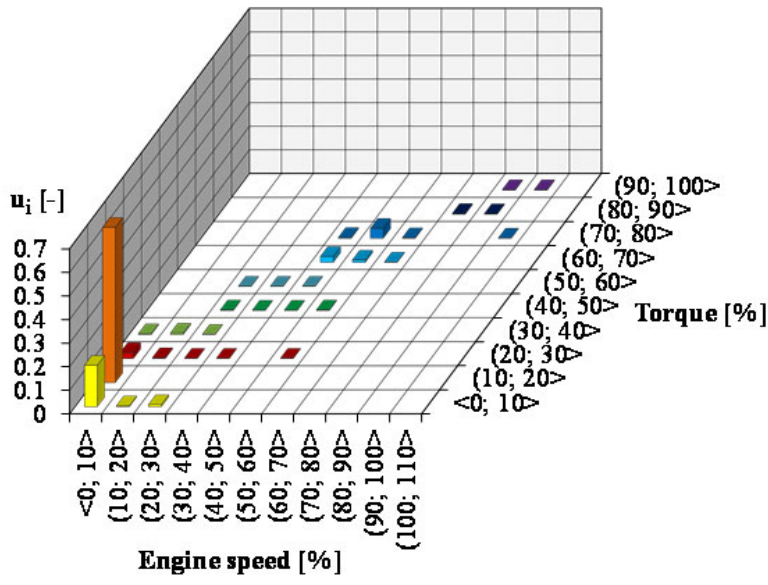

Fig. 7. Time density characteristic for the vehicle driving on the track with a load of 120 tons presented in the engine speed and load intervals

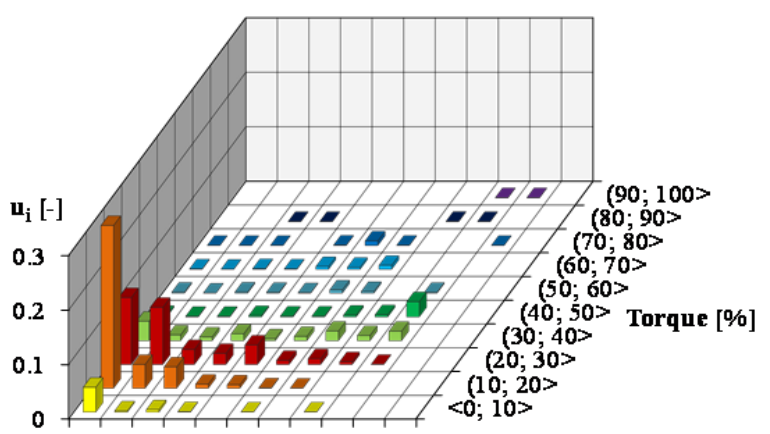

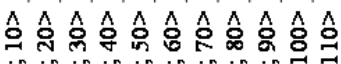

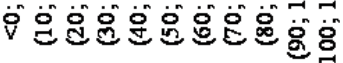

Engine speed [\%]

Fig. 8. Time density characteristic for the whole test drive cycle presented in the engine speed and load intervals

\section{Comparison of legislative guidelines with real operation}

Based on the previously obtained operating parameters, the characteristics of the absolute difference in operating 
time share between the NRTC test and the real drive of the road-rail tractor were created (Figure 9). The characteristics were limited to the values relevant to the tests (exceeding 1\% share of operating time).

The largest difference in the share of operating time $(29 \%)$ occurred in the parameters range within the engine speed range $\langle 0 \% ; 10 \%\rangle$ and torque range $(10 \%$; $20 \%\rangle$. This range of operating points with the largest difference in the operating time share is characterized by a low engine speed range of $\langle 0 \% ; 20 \%\rangle$ and low torque values in the range $(10 \% ; 30 \%)$, in which the values obtained exceed the values determined in the NRTC test - marked in red in the figure. Significant differences $(25 \%)$ occurred also in the range of high engine rotational speeds $(70 \% ; 110 \%)$ and at medium and heavy loads $(50 \% ; 100 \%)$. The presented range of operating points includes the points in which the values determined for the NRTC test exceeded the values obtained during the test - marked in blue in the figure.

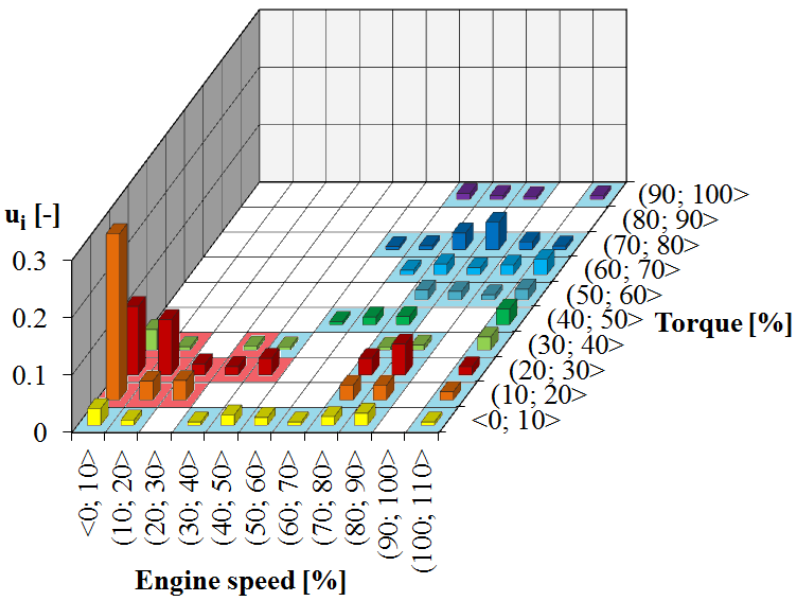

Fig. 9. The absolute difference in the operating time share between the NRTC test and the real driving test of the vehicle in the engine speed and load ranges: $\bullet-$ values greater than in the NRTC test; - - values smaller than in the NRTC test

The time density analysis was supplemented by the study of the specific exhaust emissions. The results obtained were the difference between the actual vehicle emission and the amount of pollutants found in the ambient air. They were divided into the five previously presented measuring cycles. In addition, overall ecological indicators for the entire test were presented.

The red line shown in Figure 10 marks the limit values for all toxic exhaust compounds as defined in the Stage IV norm. For carbon oxides, all cycles met the emission limit of $5 \mathrm{~g} / \mathrm{kWh}$, with the highest value measured for the first stage at $1.35 \mathrm{~g} / \mathrm{kWh}$. During the first cycle, the highest values of nitrogen oxide emissions $(3.78 \mathrm{~g} / \mathrm{kWh})$ and hydrocarbons $(0.8 \mathrm{~g} / \mathrm{kWh})$ were also observed. It should be noted that the $\mathrm{NO}_{\mathrm{x}}$ emission limit of $0.4 \mathrm{~g} / \mathrm{kWh}$ was met only for the cycle where the vehicle was switching to tracks. For hydrocarbons, none of the cycles were found to meet the $\mathrm{HC}$ emissions limit of $0.19 \mathrm{~g} / \mathrm{kWh}$. With respect to solid particles, the highest value of $0.13 \mathrm{mg} / \mathrm{kWh}$ was obtained during cycle IV. Stages I-IV were characterized by negative values which was caused by a significant concentration of PM in the ambient air. During all the drive cycles, the particulate emission limit of 0.025 $\mathrm{g} / \mathrm{kWh}$ has been met. In terms of total emissions from the test, the vehicle met only the CO limit defined in the emission norms, as well as PM thanks to the effect of the particulate filter.

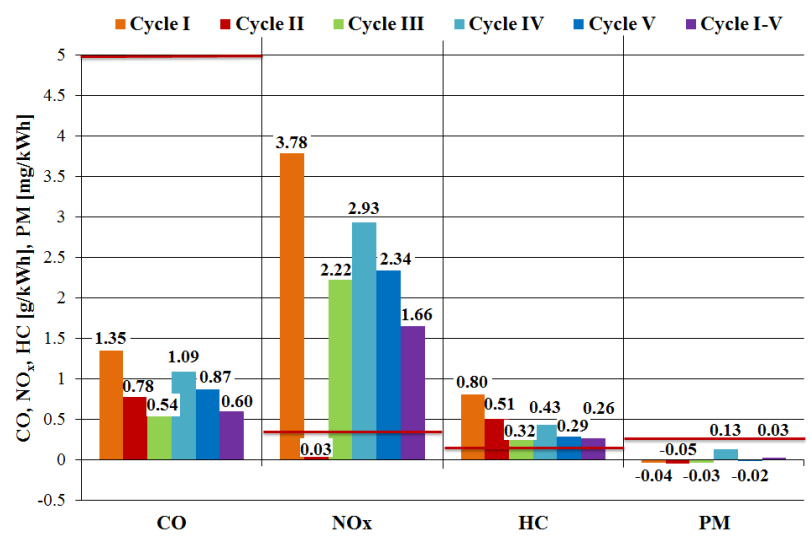

Fig. 8. 31 Specific emissions from the test vehicle

\section{Guidelines for testing under real operating conditions - Real Road-Rail Emission (RRRE)}

The performed tests should reflect the emissions from real road and rail traffic. The level of actual emissions often exceeds the emission values obtained when testing in laboratory conditions (in particular with regard to $\mathrm{NO}_{\mathrm{x}}$ ). Therefore, it is necessary to develop a new test procedure performed in real conditions for road-rail vehicles (RRRE - Real Road-Rail Emission), which will reflect the emission measured during its real operation. To determine the emission of harmful compounds in conditions of real operation (referring to Regulation (EC) No 715/2007), a number of requirements for the newly developed test are necessary. The RRRE test should cover the widest possible range of operating conditions of the propulsion system and vehicle movement to ensure compliance with the normal conditions in which the vehicles are to be used.

The tests should be carried out in dynamic conditions and in the ambient environment, for which requirements are specified in the Commission Regulation (EU) 2016/427 regarding the procedure for testing emissions in real driving conditions for light and commercial vehicles. In addition, for road-rail vehicles, it is necessary to set guidelines for the vehicle type and the equipment used.

The actual exhaust emissions should be determined in the five stages tests of vehicles reflecting the actual operation of road-rail vehicles (Table 3 ). The first of these is driving on a dirt road under normal driving conditions and at normal engine loads. The next stage should include rolling the object onto the railway tracks. The three remaining stages should relate to travel on rail tracks - with no load, with a load of $50 \%$ to $65 \%$, and 
finally with a load greater than $85 \%$ of the maximum pull weight of the moved set.

Table 3. Driving parameters of the RRRE test

\begin{tabular}{|c|l|c|c|c|}
\hline No. & Drive cycle & $\begin{array}{c}\text { Share of } \\
\text { cycle } \\
\text { duration } \\
\text { [\%] }\end{array}$ & $\begin{array}{c}\text { Mean } \\
\text { vehicle } \\
\text { speed } \\
{[\%]}\end{array}$ & $\begin{array}{c}\text { Drive } \\
\text { cycle } \\
\text { duration } \\
{[\%]}\end{array}$ \\
\hline I & $\begin{array}{l}\text { Road } \\
\text { driving }\end{array}$ & 20 & 25 & 20 \\
\hline II & $\begin{array}{l}\text { Moving } \\
\text { onto the rail } \\
\text { tracks }\end{array}$ & - & - & - \\
\hline III & $\begin{array}{l}\text { Track } \\
\text { driving with } \\
\text { no load }\end{array}$ & 20 & 20 & 20 \\
\hline IV & $\begin{array}{l}\text { Track } \\
\text { driving with } \\
\text { a load of } 90 \\
\text { tons }\end{array}$ & 40 & 10 & 40 \\
\hline V & $\begin{array}{l}\text { Track } \\
\text { driving with } \\
\text { a load of } \\
140 \text { tons }\end{array}$ & 20 & 5 & 20 \\
\hline Shares margin of tolerance $\pm 10 \%$ & \\
\hline
\end{tabular}

Operational and transit requirements should include:

- The duration of the entire test should be no less than 60 minutes but should not exceed 90 minutes.

- Shares of time spent driving in individual stages. The cycles should be split into approximately $20 \%$ for driving on a dirt road, $20 \%$ for track travel without load and with a load of over $85 \%$ and $40 \%$ when travelling on track with a load of $50-65 \%$. The accuracy of the obtained parameters should be within $\pm 10 \%$, excluding the process of rolling onto tracks. The cycle of driving on rail track with a load from $50 \%$ to $65 \%$ must, however, reach a driving share of no less than $35 \%$ of the total test duration.

- Average drive speed, including idling, should not exceed $35 \%$ of the maximum vehicle speed. Idling should comprise at least $30 \%$ of the total driving time when moving on the track. The average road travel speed should be approximately $25 \%$ of the maximum vehicle speed. For the drive on the track, the vehicle should achieve an average speed of $20 \%$ for drive without load, $10 \%$ for the drive with a load of 50$65 \%$ and $5 \%$ for a drive with a load of not less than $85 \%$.

- The route should be chosen in such a way that the test can be carried out without interruption, and the data is constantly being recorded by the test equipment. The road route travelled should be flat and paved, while for driving on the track it should include a section of a flat track with a maximum slope of $2 \%$.
- The test driver should have experience in working with this type of machine, perform cycles as standard, without matching the driving style, in the defined range of stress and focus (an example of evaluation can be found in [13]).

The requirements for apparatus should include:

- The test equipment must include analyzers belonging to the PEMS group to measure the concentration of exhaust gases and particulates.

- The tests should be supplemented with the exhaust emissions assessment measured by means of the mobile analyzer.

- Electricity to power the measuring devices should be supplied by means of an external power supply, energy should not be drawn directly or indirectly from the engine of the tested vehicle.

- The installation of the measuring devices should be carried out in such a way as to minimize its impact on exhaust emissions from the vehicle and its operation.

- Determining the exhaust mass flow should be performed with the use of measuring equipment functioning independently of the vehicle and not by relying on data from its diagnostic system.

- The location, elevation and speed of the vehicle should be determined using the global positioning system.

- The measurement of environmental conditions such as temperature, relative humidity, or atmospheric pressure should be carried out with the help of sensors or other devices that are not part of the vehicle equipment, it is acceptable to use special onboard systems [14].

- The tested parameters should be measured and recorded at a constant data acquisition frequency of 1 $\mathrm{Hz}$ or more.

\section{Test proposal for the assessment of exhaust emissions of road-rail vehicles in real operating conditions}

The test presented in this chapter is a proposal for testing road-rail vehicles. According to the guidelines presented, the authors of the study examined eight road-rail tractors. The obtained results confirm the possibility of achieving repeatability of the measurement tests and the implementation of a broader assessment of the ecological indicators of the vehicles of the tested group.

The conducted research indicates that the test for assessing pollutants for road-rail vehicles should include a larger share of operating time in the engine range characterized by low rotational speed $\langle 0 \% ; 20 \%\rangle$ and low torque values $(10 \% ; 30 \%\rangle$ in relation to the NRTC cycle. It would also be necessary to limit the share of work points in the range of high rotational speeds $(70 \%$; $110 \%\rangle$ and medium and high loads $(50 \% ; 100 \%)$. It is 
also reasonable to extend the test duration from $1240 \mathrm{~s}$ to at least $3600 \mathrm{~s}$ to obtain a larger amount of measurement data. Dividing the test into the stages presented in this article allows for a thorough analysis of the data (Figure 11). The stage of driving on road should be characterized by a high variability of engine parameters for the range of small and medium parameters. At the same time, it should not exceed $30 \%$ of the total drive duration of the whole test. Rolling onto the rail track is to take place without interruption immediately after the end of the road drive cycle and immediately before the start of the track drive cycle. The track drive cycle should be characterized by lower variability of work parameters than is the case during the first stage, in the drive without load, the engine operation parameters range is to include medium and small values in the area of variability of the drive system operating parameters. For the drive with a load of $50-65 \%$, the vehicle should operate at small and medium loads and achieve high values of crankshaft rotational speed. This stage is characterized by the largest share of operating time, not less than $35 \%$ of the entire test duration. The drive stage with a load of more than $85 \%$ is characterized by variability of parameters in a wide range of engine operation.

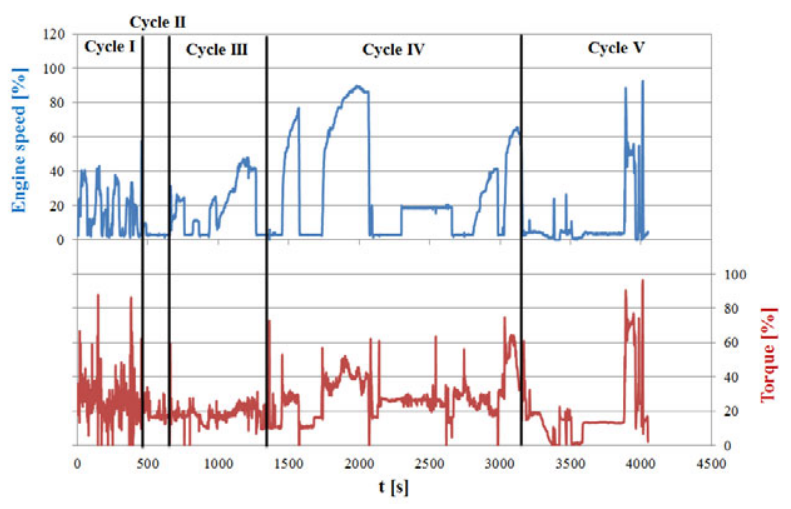

Fig. 11. Characteristics of engine rotational speed and torque expressed in the RRRE test

\section{Conclusions}

Due to the need to protect the environment, an increasing public awareness, as well as the development of more precise and capable emission measuring devices, various types of research are conducted to assess the exhaust emissions from various vehicle groups. Currently, normative guidelines for real driving tests for passenger cars and heavy vehicles are introduced. Leading research institutes deal with the issues of field testing of other vehicle and machine groups, including road-rail facilities. The article presents the tests of a road-rail tractor in accordance with the adopted original research method.

Characteristics of time density as a function of engine rotational speed and load created based on the operating parameters as determined in the NRTC test are characterized by the largest share of $50 \%$ operating time in the range of high engine rotational speeds of $\langle 50 \%$; $110 \%\rangle$ and small and medium torque values at $\langle 0 \%$;
$60 \%\rangle$. Characteristics of time density as a function of engine rotational speed and load created based on the operating parameters as determined in the designed custom test, are characterized by the largest share of $60 \%$ operating time in the range of low engine rotational speeds $\langle 0 \% ; 30 \%\rangle$ and small loads $(10 \% ; 30 \%\rangle$.

Specific emission values obtained throughout the whole test exceeded the emission limit values for nitrogen oxides $(1.66 \mathrm{~g} / \mathrm{kWh})$ and hydrocarbons $(0.26$ $\mathrm{g} / \mathrm{kWh}$ ). The exhaust components whose emission values met the limit values were the carbon oxides $(0.6 \mathrm{~g} / \mathrm{kWh})$ and solid particles $(0.03 \mathrm{mg} / \mathrm{kWh})$.

Based on their research experience, the authors proposed a new test cycle designed specifically and exclusively for road-rail vehicles. It unifies the measurement method of road-rail vehicles and modifies the currently applicable type approval tests, which, as it as shown in the article, do not accurately reflect the real operation of the tested vehicles.

The guidelines for the test implementation were also described in the article. They refer mainly to the method of conducting measurements, which should be divided into five stages, including both driving on a paved road, rolling onto the tracks, as well as driving on tracks with various additional loads. Some focus was also placed on operational requirements and specific requirements for the tested vehicles, where the vehicle operating time shares, their average speed and duration of individual measurement cycles were all determined. The requirements for the measuring equipment that can be used to measure the concentration of exhaust gases and particulates and the exhaust emissions in ambient air were also described. Further research includes plans to define the adjustment coefficients - CF (Conformity Factor). They will describe the permitted level of exceeding the emission limit values given in the currently applicable regulations. However, to accomplish this, it is necessary to carry out research work on a larger group of vehicles.

\section{References}

1. M. Bajerlein, P. Daszkiewicz, M. Dobrzyński, Ł. Rymaniak, M. Siedlecki, Combustion Engines, 3, 800-804 (2015)

2. P. Fuć, P. Lijewski, A. Ziółkowski, M. Siedlecki, Combustion Engines, 3, 417-424 (2015)

3. J. Merkisz, P. Fuć, J. Pielecha, Publishing House of the Warsaw University of Technology (2014)

4. J. Merkisz, D. Michalak, M. Bajerlein, P. Molik, Ł. Rymaniak, A. Ziółkowski. Autobusy - Technika, Eksploatacja, Systemy Transportowe, 3, 111-119 (2012)

5. J. Merkisz, D. Michalak, M. Bajerlein, M. Nowak, Ł. Rymaniak, A. Ziółkowski, Autobusy - Technika, Eksploatacja, Systemy Transportowe, 3, 104-110 (2012).

6. J. Merkisz, J. Pielecha, P.Fuć. The Committee of Civil and Water Engineering of PAN (2013) 
7. J. Merkisz, Ł. Rymaniak Combustion Engines, 3, Pages: 21-26 (2017)

8. B. Kurc, Journal Of Solid State Electrochemistry, 18, 2035-2046 (2014)

9. J. Merkisz, P. Fuć, 10th WFC10 Congres Proceedings, 3, 479-483(2008)

10. K.T. Wojciechowski, J. Merkisz, P. Fuć, J. Tomankiewicz, R. Zybała, J. Leszczyński, P. Lijewski P. Nieroda, Combustion Engines, 3, 60-71 (2013)
11. R. Jachimowski, P. Golebiowski, M. Izdebski, D. Pyza, Archives of Transport, 41, 31-42 (2017)

12. K. Andrzejczak, J. Selech, Transport Problems, 12, 103-111 (2017)

13. D. Dolinski, E. Odachowska, Accident Analysis And Prevention, 115, 73-78, (2018)

14. J. Merkisz, R. Grzeszczyk, Advanced Microsystems For Automotive Applications 2010: Smart Systems For Green Cars And Safe Mobility, Edited by: G. Meyer, J. Valldorf, 347-356, (2010) 